\title{
Paper Burning and Associated Pollution Problems in Higher Educational Institutions of Ethiopia; The Need and Potential for Recycling
}

Mekonnen Amberber* and Yitayal Addis

Department of Environmental Science, College of Natural and Computational Sciences, Kotebe Metropolitan University, Ethiopia

\begin{abstract}
Higher educational institutions use large amount of paper for students' assessment each year. As recycling is one of the best options for efficient material utilization and waste management, the potential in higher education institutions was assessed taking Kotebe Metropolitan University (KMU) and Ethiopian Civil Service University (ECSU) as sampling site. The aim was to evaluate the human health and environmental consequences of storing and burning assessment paper there by turning the cause of the damage to sustainable utilization through proposing recycling. Accordingly, the potential criteria air pollutant emissions while burning assessment papers, heavy metal concentrations in the ash of the burned paper and macro-nutrients were determined using Aero-Qual series 300 in open burning at KMU, and Atomic Absorption Spectrophotometer at JIJE Analytical Testing Service Laboratory, respectively. It was found that the average emissions for $\mathrm{CO}(119.67 \mathrm{ppm}), \mathrm{CO}_{2}(1700 \mathrm{ppm}), \mathrm{SO}_{2}(038 \mathrm{ppm})$, VOCs $(3749 \mathrm{ppm})$ and $\mathrm{NOx}(0.10 \mathrm{ppm})$ were recorded. The concentration of $\mathrm{CO}, \mathrm{SO}_{2}$ and $\mathrm{NOx}$ were significantly higher than the guidelines recommended by $\mathrm{WHO}$ and other international organizations. The paired sample $\mathrm{t}$-test between white paper and the printed one showed significant difference $(\mathrm{p}<0.05)$ on the parameters $\mathrm{CO}_{2}$ and NOx . Similarly, the heavy metal analysis result indicated that $\mathrm{Cd}(0.47 \mathrm{mg} / \mathrm{kg})$, and $\mathrm{Pb}(0.48 \mathrm{mg} / \mathrm{l})$ were detected from the ash of printed paper. Moreover, the average $\mathrm{pH}$ and macro-nutrients (NPK values) of the printed paper were 9.07, $0.83 \%, 40.88 \mathrm{ppm}$ and $83.68 \mathrm{ppm}$ respectively. About 35, 000 ream of paper is burnt in each of the institutions per year, and $69 \%$ of the respondents (instructors) were volunteered and were ready, to provide assessment paper for recycling which shows that there exist considerable potential for paper recycling in HEIs. Therefore, the researchers need to recommend that paper recycling should be taken as an integrated system of the activities in HEIs.
\end{abstract}

Keywords: Attitude; Paper recycling; Heavy metals; Air pollutants; Higher learning institutions

\section{Introduction}

Solid waste management is one of the basic essential services provided by municipal authorities to keep urban centers tidy. "The adverse impacts of waste management are best addressed by establishing integrated programs where all types of waste and all facets of the waste management process are considered together. The long-term goal should be to develop an integrated waste management system and build the technical, financial, and administrative capacity to manage and sustain it" [1].

Waste reduction is a fundamental tenet of sustainability, and recycling is an integral part of any solid waste management plan. It's one of the four Rs we are all familiar with: reduce, reuse and recycle, practiced in that order of importance [2].

Paper and cardboard are reported as the second largest component of domestic waste next to organic waste which contributes about $13 \%$ of the total domestic solid waste [2]. Similarly, waste composition data in different Universities show that paper alone constitutes more than $11 \%[3,4]$ which is still the second in volume compared to other solid waste components.

Developed countries have already started recycling papers efficiently. For example, the Sydney plant ark environmental foundation [5] reported that manufacturing paper and cardboard products from recycled material not only conserve trees, it also uses consumed up to $50 \%$ less energy and $90 \%$ less water than making them from raw materials. This report also stated that for every 100 reams of recycled office paper that is printed doubled sided, the savings are estimated at two trees, more than one tone of greenhouse gases and almost a cubic meter of landfill space, compared with using 100 reams of non-recycled paper or printing single-sided. Moreover, recycling practices in USA shows that recycling rate for office type paper is $74.2 \%$ in 2009 [1].

On the contrary, paper recycling practices are low in developing countries; rather they utilize recycled products imported from developed countries [6]. In addition, the waste collection method is reported as informal and in unorganized manner [7]. In the case of Ethiopia, there are no well-established waste paper recycling system, strategies and studies.

Higher educational institutions (HEIs) purchase considerable amount of paper each year which could require significant amount of budgeting. Assessment paper takes the largest share for the utilization of the paper that is openly burned after utilization which is not environmentally benign activity. Moreover, there could be ecological, social and economical advantage both for the recycling company, as it utilizes waste to establish a sustainable business and to generate income, and higher education institutions if the paper gets recycled and purchased back with a minimum cost.

Lack of such scientific knowledge and technology may let

*Corresponding author: Amberber M, Department of Environmental Science, College of Natural and Computational Sciences, Kotebe Metropolitan University, Ethiopia, Tel: +251-913714680; E-mail: gmekonnena@gmail.com

Received July 12, 2017; Accepted July 20, 2017 ; Published July 27, 2017

Citation: Amberber M, Addis Y (2017) Paper Burning and Associated Pollution Problems in Higher Educational Institutions of Ethiopia; The Need and Potential for Recycling. Int J Waste Resour 7: 290. doi: 10.4172/2252-5211.1000290

Copyright: @ 2017 Amberber M, et al. This is an open-access article distributed under the terms of the Creative Commons Attribution License, which permits unrestricted use, distribution, and reproduction in any medium, provided the original author and source are credited. 
destruction of ecology /environment and economical/social benefits continue unnoticed. The current alarming expansions of universities in number and increasing consumption rate in Addis Ababa city and the entire country has initiated this study.

Therefore, integrated sourcing of used papers and purchasing of recycled papers among recycle companies and educational institutions should be made for the sustainable use of waste materials as a raw material for production, considering the environmental impacts of manufacturing including those associated with processing scrap paper and deinking.

\section{Materials and Methods}

\section{General approach}

This study was conducted in two governmental Universities in Addis Ababa: Kotebe Metropolitan University and Ethiopian Civil Service University. In addition to Universities, paper manufacturing companies and small scale paper recycling enterprises were also communicated to collect the data.

The data was collected from departments, property offices, president office, different departments, and finance and disbursement office of the two Universities by using pre prepared semi-structured questionnaire. In order to address the paper consumption pattern (the amount of paper purchased per year and allocated for assessment and other office activities per year for each university), a total of about 422 interviewed informants were selected after preliminary survey out of which 100 key informants (lecturers and above ranked instructors) were randomly selected from purposely selected colleges and faculties and assessed the awareness level, willingness to provide assessment paper for university delegated companies and reused the recycled paper for assessment and other office activities.

\section{Determination of pollutants}

The concentrations of the selected pollutants $\left(\mathrm{CO}, \mathrm{CO} 2, \mathrm{SO}_{2}, \mathrm{NOx}\right.$ and VOCs) were measured using Aero-Qual series 300. Lead ( $\mathrm{Pb})$ and cadmium (Cd) were measured as they could be components included during ink manufacturing (Better paper project, 2015). Concentration of $\mathrm{Pb}$, and $\mathrm{Cd}$ were determined in the sludge using furnace atomic absorption spectrometry and flame atomic absorption spectrometry. The PG-990 Atomic Absorption Spectrophotometer equipped with a graphite furnace and ASC- 990 auto-sampler for GFAAS and ASC900 auto-sampler for flame was used for determinations [8] at JIJE Analytical Testing Service Laboratory.

Determination of $\mathrm{pH}$ and macro-nutrients on the sludge: Nitrogen, Phosphorus and Potassium (NPK) and $\mathrm{pH}$ values of the sludge were determined following the APHA [9] procedures at JIJE Analytical Testing Service Laboratory.

\section{Data analysis}

The collected data were analyzed and summarized using descriptive statistics using excel and significant differences at 0.05 levels was analyzed in paired samples t-test using SPSS version 20 . Finally the results were reported in mean \pm SD.

\section{Results and Discussion}

\section{Quantity of paper purchased and used for assessment}

From the sampled public Universities, KMU and ECSU, the amount of paper utilized per year for assessment and associated activities is presented in Figure 1. As it's indicated in Figure 1, the consumption rate as well as the burning rate of assessment paper is increasing annually which highly associated with the universities expansion and the increase in yearly intake of students. This is one indication of the amount of burned paper and associated risks (Table 1), and waste paper potential for recycling purpose.

\section{Environmental emissions during burning paper}

The $34 \%$ of the instructors responded that they manage waste papers by burning the assessment paper each year. Burning paper is not environmentally sound because during burning particulates and gaseous air pollutants are emitted to the atmosphere. Besides, recycling the paper provides double benefits. The first one is keeping environmental quality and the other one is that it can be used as a raw material to produce other paper based products rather than using trees. The potential gases that could be emitted during burning are measured and the report is presented in Table 1.

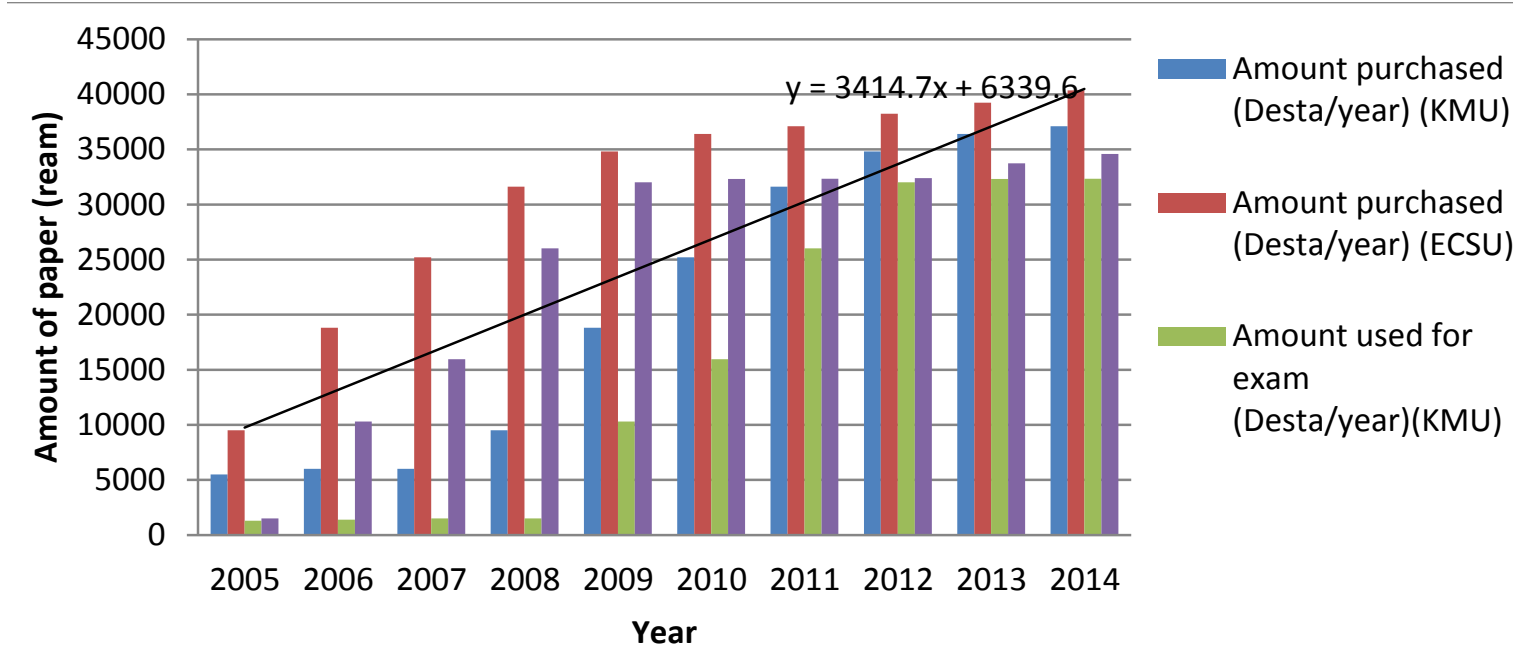

Figure 1: Amount of paper purchased versus used for assessment. 


\begin{tabular}{|c|c|c|c|c|c|c|}
\hline \multirow{2}{*}{ Pollutants } & \multicolumn{2}{|c|}{ Concentration (ppm) } & \multicolumn{2}{|c|}{ Paired sample t-test result } & \multirow{2}{*}{$\begin{array}{l}\text { Guide line concentration } \\
(\mathrm{ppm})\end{array}$} & \multirow{2}{*}{ Exposure duration } \\
\hline & White paper & Printed paper & t-value & $p$-value & & \\
\hline \multirow{2}{*}{ co } & \multirow{2}{*}{$84.67 \pm 10.21$} & \multirow{2}{*}{$119.67 \pm 26.31$} & \multirow{2}{*}{2.917} & \multirow{2}{*}{0.100} & 9 & 8 hours \\
\hline & & & & & 35 & 1 hour \\
\hline $\mathrm{CO}_{2}$ & $384.33 \pm 35.02$ & $1700 \pm 157.16$ & 14.66 & 0.005 & & \\
\hline \multirow{3}{*}{$\mathrm{SO}_{2}$} & \multirow{3}{*}{$0.37 \pm 0.16$} & \multirow{3}{*}{$0.38 \pm 0.14$} & \multirow{3}{*}{0.111} & \multirow{3}{*}{0.922} & 0.20 & 1 hour \\
\hline & & & & & 0.08 & 24hours \\
\hline & & & & & 0.02 & 1 year \\
\hline VOCs & $3047 \pm 104.93$ & $3749.33 \pm 229.01$ & 3.647 & 0.068 & & \\
\hline $\mathrm{NO}_{x}$ & $\mathrm{BDL}$ & $0.19 \pm 0.03$ & 1.110 & 0.383 & & \\
\hline
\end{tabular}

Emission of $\mathrm{CO}, \mathrm{CO}_{2}, \mathrm{SO}_{2}$, Volatile organic compounds (VOCs) and nitrogen oxides (NOx) were determined. These gases are selected as they are considered to be the criteria air pollutants (commonly emitted and detrimental to health) except $\mathrm{CO}_{2}$. $\mathrm{CO}_{2}$ is considered as it is the common greenhouse gas that has been given attention by the scientific community. As it can be seen from Table 1, the concentration of the air pollutants in this study is higher than the values in the guideline. If one is obliged to burn a paper, it is better to keep far away to minimizing the duration of exposure once it is ignited. Generally, the concentrations of each of the gaseous pollutants in burnt assessment papers are high enough to pose health risks. Therefore, it is better to recycle such papers than burning.

In addition, the concentration of each of the air pollutants emitted while burning the printed paper is larger than the non-printed one. This might be due to the additional pollutant produced by the printing ink. However, the difference is statistically significant $(\mathrm{p}<0.05)$ only for $\mathrm{CO}_{2}$ and NOx (Table 1). This indicates that much of the ingredients in the printing ink are converted to $\mathrm{CO}_{2}$ and oxides of nitrogen (NOx).

\section{Total projected emission}

The amount of gaseous pollutants released to the atmosphere annually is estimated by considering the total amount of assessment papers, and their potential concentration for the consecutive six years and the result is presented in Figure 2.

\section{Estimated total emission of heavy metals per year}

Not only air pollutants but also heavy metals on ash of burned assessment papers that could be mixed to soil were determined and results are shown in Table 2. It was found that the concentration of $\mathrm{Pb}$ and $\mathrm{Cd}$ in printed paper is significantly higher $(\mathrm{p}<0.05)$ than their corresponding concentration on white paper. The source for the additional concentration on printed paper could be the ink. $\mathrm{Pb}$ and $\mathrm{Cd}$ are among toxic heavy metals that results in detrimental health effects. $\mathrm{Pb}$ has a number of toxic effects, including inhibition of the synthesis of hemoglobin and adversely affects the central and peripheral nervous systems and the kidneys. Cd adversely affects several important enzymes; it can also cause painful osteomalacia (bone disease) and kidney damage. Inhalation of cadmium oxide dusts and fumes results in cadmium pneumonitis characterized by edema and pulmonary epithelium necrosis (death of tissue lining lungs) [10]. This shows that assessment papers had better be recycled than be burnt to prevent toxic metal exposure and the associated risks.

\section{$\mathrm{pH}$ and macro-nutrients}

The result showed that the $\mathrm{pH}$ of white paper is slightly alkaline (7.98) and that of the printed paper sample is quite alkaline with an average $\mathrm{pH}$ of 9.07 (Table 3). The $\mathrm{pH}$, total nitrogen (TN), total

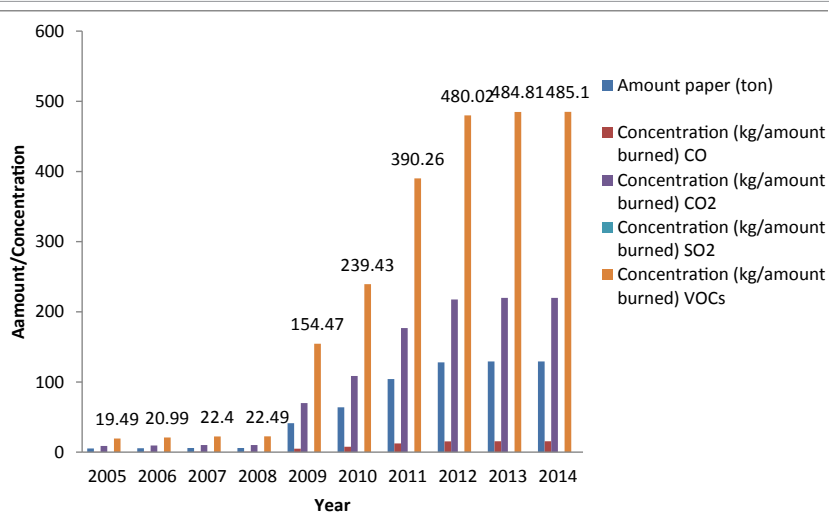

Figure 2: Annual projected gaseous pollutant emissions.

\begin{tabular}{|c|c|c|c|c|}
\hline \multirow{2}{*}{ Heavy Metal } & \multicolumn{2}{|c|}{ Concentration (ppm) } & \multicolumn{2}{c|}{$\begin{array}{c}\text { Paired sample t-test test } \\
\text { result }\end{array}$} \\
\hline & White paper & Printed paper & t-value & -value \\
\hline Pb & $0.39 \pm 0.13$ & $0.84 \pm 0.16$ & 4.041 & 0.046 \\
\hline Cd & $0.33 \pm 0.25$ & $0.47 \pm 0.24$ & 15.11 & 0.004 \\
\hline
\end{tabular}

Table 2: Heavy metal concentration on paper ash.

\begin{tabular}{|c|c|c|c|c|}
\hline \multirow{2}{*}{ Heavy Metal } & \multicolumn{2}{|c|}{ Value } & \multicolumn{2}{c|}{$\begin{array}{c}\text { Paired sample t-test } \\
\text { test result }\end{array}$} \\
\cline { 2 - 5 } & White paper & Printed paper & t-value & p-value \\
\hline pH & $7.98 \pm 0.32$ & $9.07 \pm 0.24$ & 2.092 & 0.172 \\
\hline Moisture content (\%) & $3.39 \pm 0.15$ & $2.89 \pm 0.04$ & - & \\
\hline TN (\%) & $0.17 \pm 0.09$ & $0.83 \pm 0.06$ & 15.684 & 0.004 \\
\hline TP (ppm) & $23.49 \pm 0.69$ & $40.88 \pm 1.38$ & 36.039 & 0.001 \\
\hline K (ppm) & $70.54 \pm 1.83$ & $83.68 \pm 1.93$ & 118.850 & 0.000 \\
\hline
\end{tabular}

Table 3: $\mathrm{pH}$ and macronutrient level of white paper and printed paper.

phosphorus (TP) and potassium (K) content of the printed paper are higher than the one on the white paper. The paired sample t-test result indicated that the difference on the values of macro-nutrients on printed and white paper is significantly $(p<0.05)$. This indicates that printed paper could be composted and used to fertilize acidic soils that contain sulfur which utilize $\mathrm{Pb}$ and $\mathrm{Cd}$ to precipitate in the form of $\mathrm{PbS}$ and CdS, respectively.

\section{Instructors' perception and willingness on assessment paper handling}

A total of 100 lecturers (46 and 54 work at KMU and ECSU, respectively) were participated in this assessment. Their perception on the use of assessment papers is presented in Figure 3. As it is indicated in Figure 3, only12 (12\%) of the respondents were experienced in 


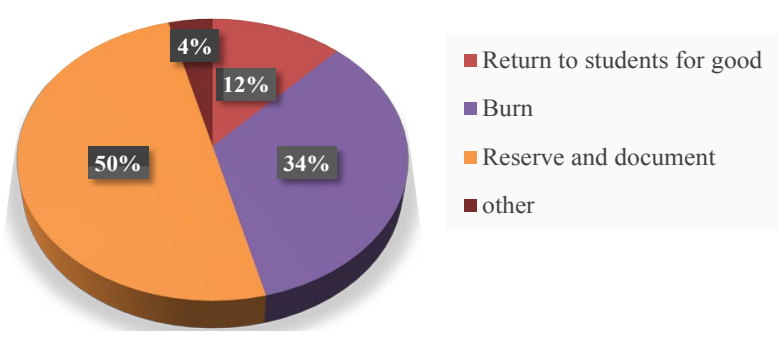

Figure 3: Instructors experiences on assessment paper.

returning the assessment paper for the students after correction to use it for future reference. Although, $50 \%$ of the respondents preferred to reserve and document the assessment papers in their offices after correction, they pointed out that they suffer from shortage of storage space and unpleasant odor results in decrease aesthetic value of the offices and health problems like asthma. Those who burned the assessment papers put the prevention of student dependency on the assessment papers in case they obtain, to get enough space for storage, to minimize unpleasant odor that cause health problems and to maintain the aesthetic value of the office as the main reasons. Moreover, $74.07 \%$ and $63.05 \%$ of the respondents of ECSU and KMU respectively, indicated that they are volunteer and ready to provide used paper to delegated company for recycling as indicated in Figure 4.

\section{Conclusion}

Based on the findings, it is possible to conclude that there is huge potential of waste paper for recycling in higher education institutions. The paper recycling projects could minimize the amount of criteria air pollutants (CO, SO2, NOx, VOCs) which are detrimental to health, and the greenhouse gas $\mathrm{CO}_{2}$ as well as toxic heavy metals $(\mathrm{Pb}$ and $\mathrm{Cd}$ ). On the other hand, printed paper contains significant amount of macronutrients which could be used for fertilizer for acidic soils after composting if recycling of paper is found to be difficult. Instructors' perception on the side effects of burning and storing assessment papers and their willingness to provide for recycling along with the huge amount of paper purchased and used for assessment is indication of availability of huge potential for paper recycling in HEIs [11-13].

\section{Recommendation}

- Recycling assessment papers can be an additional business development area in higher educational institutions. Therefore, to be economically efficient and environmentally sound higher learning institutions had better establish paper recycling enterprises independently or in co-operation. If establishment of recycling company is difficult, the waste paper could be composted for nutrient recovery and soil fertilization.

- Environmental science and related departments should raise awareness among instructors to submit assessment papers to working on recycling of papers enterprises.

- The established enterprise should agree to keep assessment papers save or cut in to small pieces till processing.

\section{Acknowledgment}

This work is based on the annual financial support of Kotebe Metropolitan University for research projects. The authors greatly acknowledge this institution. Key informants of the scientific community who willingly shared their valuable perceptions and scientific knowledge and provided information about the assessment paper status of their university are also duly acknowledged.

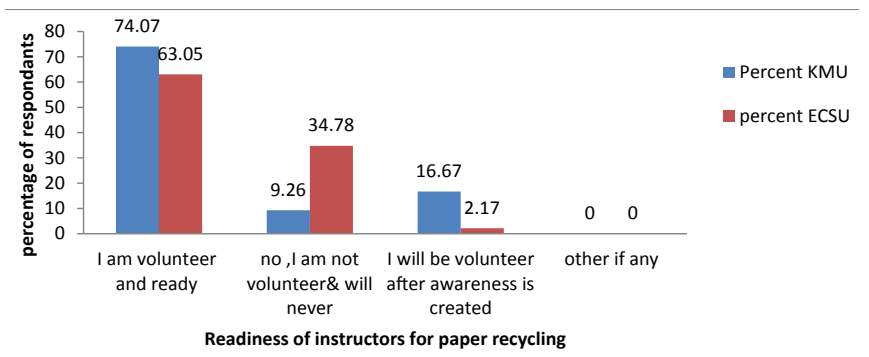

Figure 4: Volunteer and readiness to provided assessment paper for recycling company.

\section{References}

1. USAID (2009) Solid waste: Generation, handling, treatment and disposal Environmental Guidelines for Small-Scale Activities in Africa (EGSSAA).

2. Ramachandra TV (2009) Management of municipal solid waste. Teri Press, New Delhi, India.

3. Countryman (2009) An analysis of the waste composition of the residence halls of Indiana university. Prepared for the Indiana University Sustainability Task Force.

4. Guan, Yusoff (2013) Municipal solid waste characterization for a university campus, University of Malaya.

5. Sydney Planet Ark Environmental Foundation (2000) Paper recycling, recycling week fact sheet, Sydney.

6. Van Beukering PJH, Bouman MN (2001) Empirical evidence on recycling and trade of paper and lead in developed and developing countries. Elsevier 29:1717-1737.

7. Medina M (1997) Informal recycling and collection of solid wastes in developing countries: Issues and opportunities. The United Nations University, Institute of Advanced Studies.

8. APHA (1998) Standard methods for the assessment of water and wastewater. Washington DC, USA.

9. APHA (1999) Standard method for the assessment of water and waste water Washington DC, USA

10. Manahan SE (2003) Toxicological chemistry and Biochemistry. Lewis Publisher Washington DC

11. Better Paper Project (2015) Recycled paper facts, Green America.

12. EPA (2015) America's children and the environment.

13. US EPA (2010) Available and emerging technologies for reducing greenhouse gas emissions from the pulp and paper manufacturing industry. Sector Policies and Programs Division, Office of Air Quality Planning and Standards. 